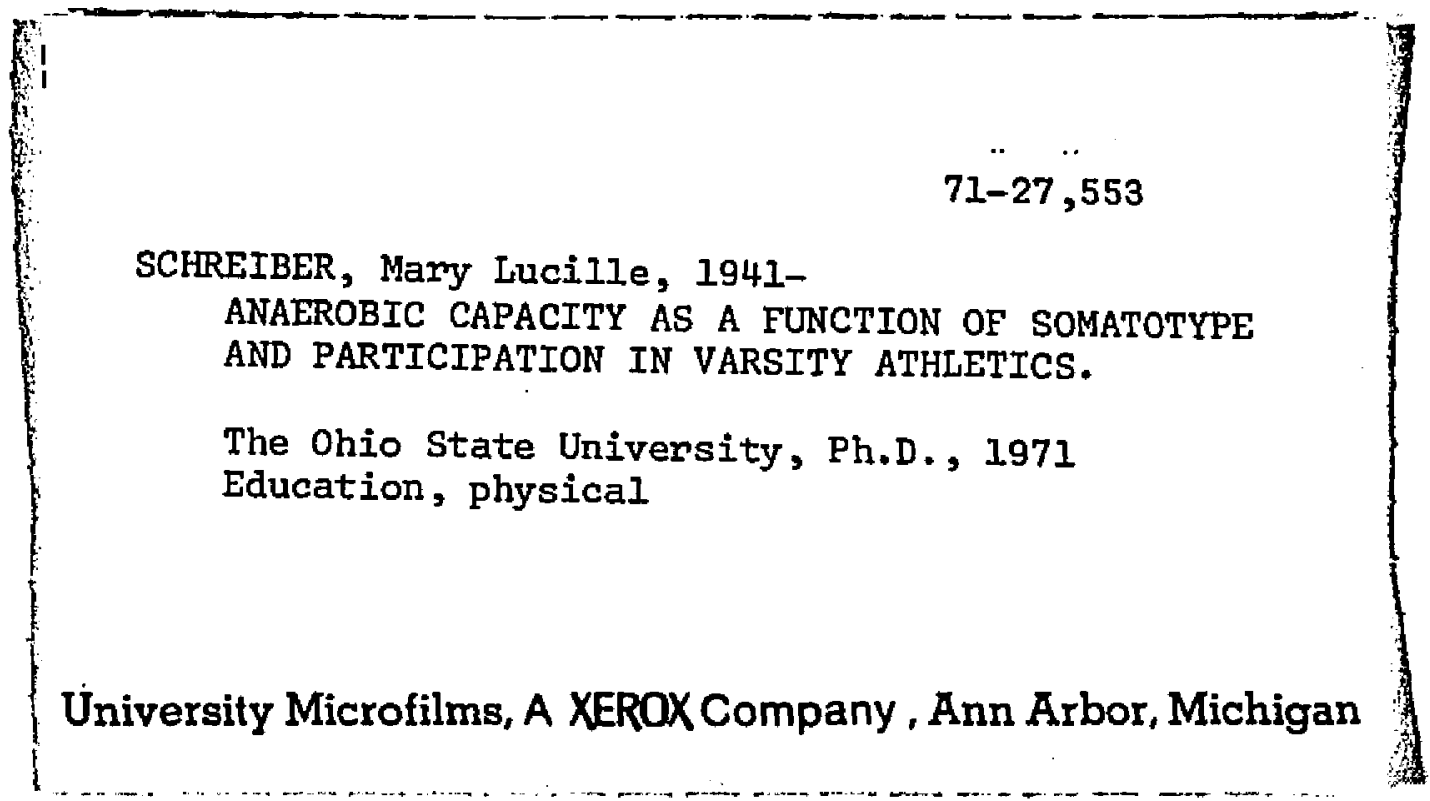

(C) Copyright by

Mary Lucille Schreiber

1971 


\title{
ANAEROBIC CAPACITY AS A FUNCTION OF SOMATOTYPE AND PARTICIPATION IN VARSITY ATHLETICS
}

\begin{abstract}
DISSERTATION
Presented in Partial Fulfillment of the Requirements for the Degree Doctor of Philosophy in the Graduate School of The ohio state University
\end{abstract}

By

Mary Iucille Schreiber, B.A., M.S. ****** *

The Ohio state University 1971

Approved by

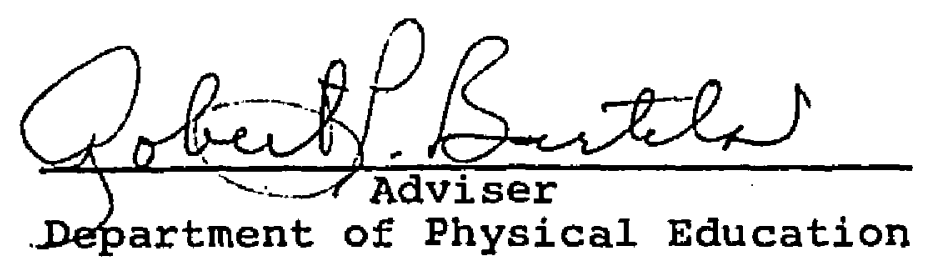




\section{PLEASE HOTE:}

Some pages have indistinct print. Filmed as received. UNIVERSITY MICROFILHS. 
To my two most influential teachers--my parents 


\section{ACKNOWLEDGMENTS}

I wish to express my sincere appreciation to my adviser, Dr. Robert Bartels, for his guidance, understanding, and patience throughout the doctoral program. To Dr. Donald K. Mathews, for his assistance in the preparation of this paper; to Dr. Warren Reeves, for his cooperation with the procuring of necessary laboratory equipment and supplies; to Martin Hall, Raul Alvarez, and Jim Peters, who helped with the collection of the data; and to Marie Goldwhite, who helped with the computer programming of the data.

Special appreciation is extended to the Department of Physical Education and Athletics at California State College at Los Angeles, without whose cooperation this study would not have been a reality. I am especially indebted to my department chairman, Dr. William Wilgus, and to the six varsity coaches whose teams were subjects in this study: Robert Miller, Reed Nilsen, Steve Haas, Gordon Maddux, Robert Enger, and Danny Bains.

Appreciation is also extended to the varsity athletes who served as my subjects and volunteered their time willingly in support of this dissertation. 
VITA

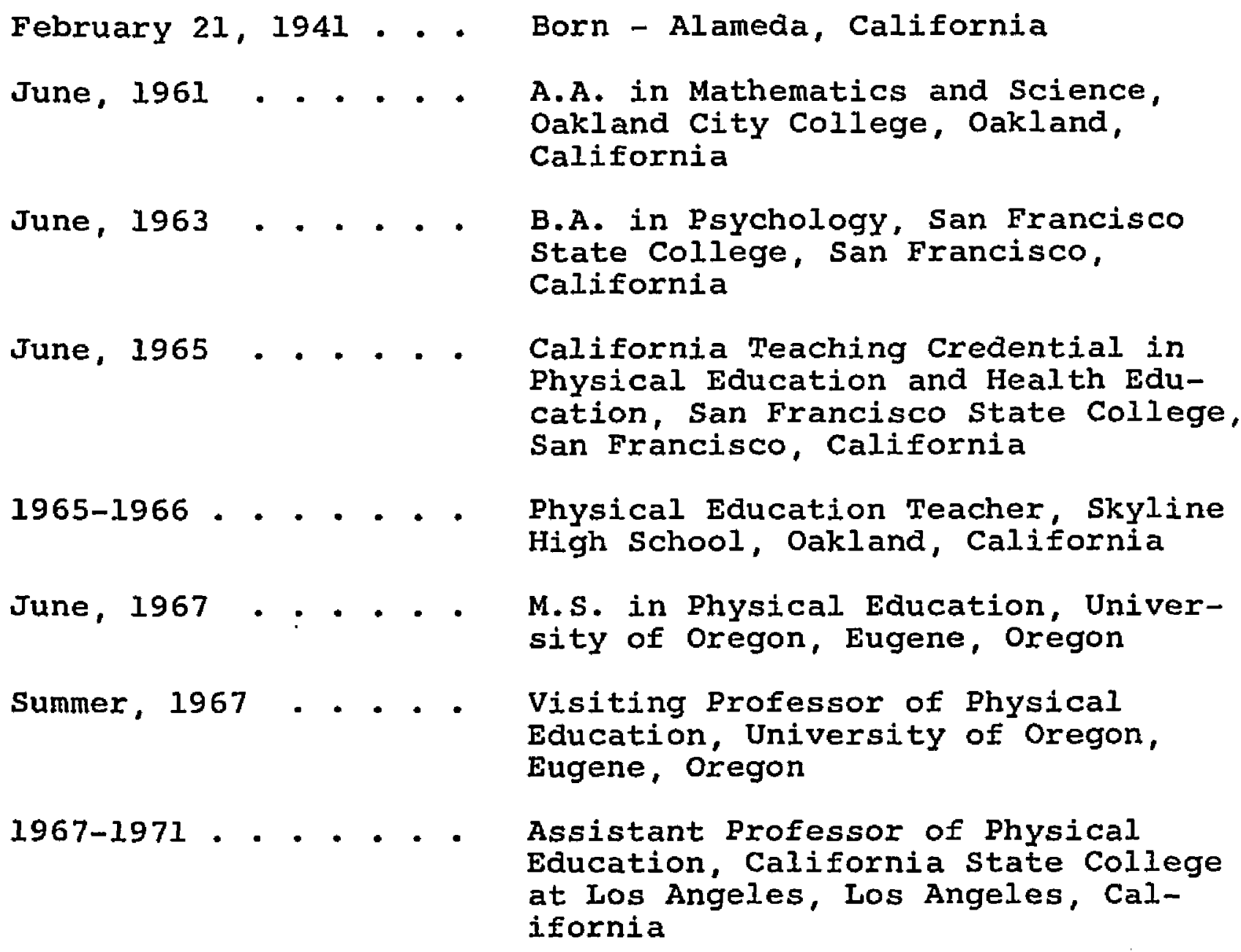

PUBLICATIONS

Women's Gymnastics. Pacific Palisades: Goodyear Publishing Company, 1969. 


\section{FIELDS OF STUDY}

Major Field: Physical Education. Professor Robert Bartels Minor Field: Teacher Education. Professor L. O. Andrews 
TABLE OF CONTENTS

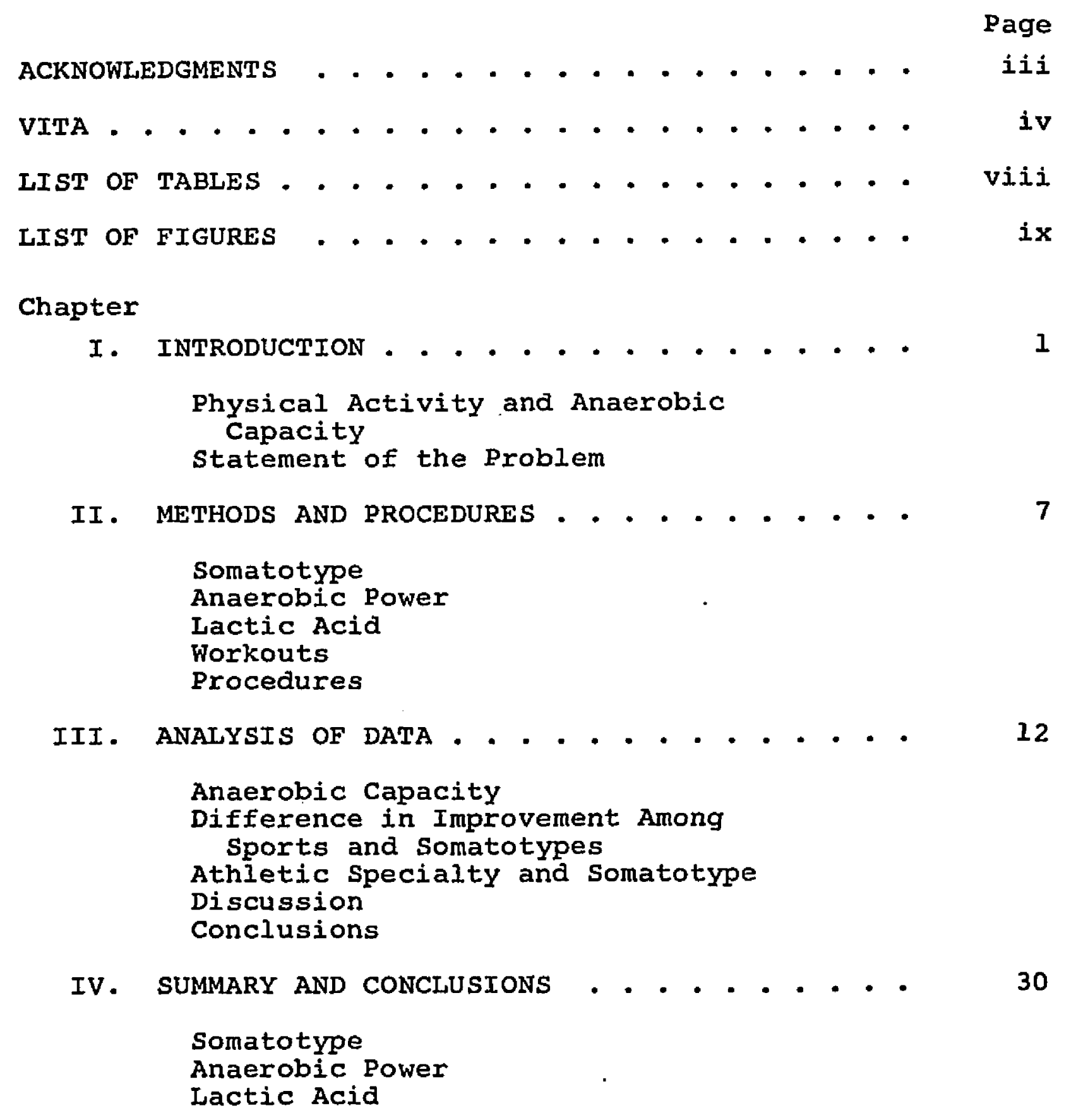


Chapter

Workouts

Summary and Conclusions

APPENDIX

A. Vital Data of Subjects . . . . . . . . . 34

B. Analysis of Covariance . . . . . . . . . 38

c. Description of Workouts . . . . . . . . . 43

D. Heath-Carter Anthropometric Somatotype

Technique ................ . 50

BIBLIOGRAPHY . . . . . . . . . . . . . . . . . . . 56

vii 


\section{LIST OF TABLES}

Table

Page

1. Vital Data of Subjects Per sport in

2. Vital Data of Subjects Per Somatotype in

3. Power in kg.-Meters/Sec. Prior to and

Following Participation in Varsity

Sports .... . . . . . . . . . . .

4. Power in kg.-Meters/Sec. of Various Somatotypes Prior to and Following Participation in Varsity Sports... . . . . . . . .

5. Blood Lactates in mg Per Cent of Athletes

Prior to and Following Participation in

Varsity sports . . . . . . . . . . .

6. Blood Lactates in mg Per Cent of Various

Somatotypes Prior to and Following

Participation in Varsity Sports . . . . . 


\section{LIST OF FIGURES}

Figure

Page

1. Somatochart of Football players . . . . . .

2. Somatochart of Soccer Players . . . . . . . . 20

3. Somatochart of Wrestlers . . . . . . . . . 21

4. Somatochart of Basketball Players . . . . . . 22

5. Somatochart of Gymnast . . . . . . . . . . 23

6. Somatochart of Cross Country Runners . . . . 24 


\section{CHAPTER I}

\section{INTRODUCTION}

The association between superior athletic performance and rigorous conditioning is eminent. One knows that to excel in athletics much time must be spent to prepare the body for the competitive contest, where optimum performance is demanded. However, it is also a well substantiated fact that training alone cannot be distinguished as the sole variable associated with excellence in performance. Nature has bestowed to some individuals structural features which complement the performance demands of specific athletic specialties. Several distinguished coaches and researchers have verified this fact. Karpovich states that there is a definite relationship between body build and phýsical aptitude ( 8 ). He advises physical educators to be cognizant of such in the selection of varsity athletes. Woody Hayes, football coach at The Ohio State University, asserts that he can identify potential varsity competitors by noting body proportions and neck circumferences. The writer, as a result of several years of coaching women's gymnastics, has noted that almost without exception outstanding female gymnasts are short and light, but exceptionally strong for their 
petite physiques. Such observations stimulated the conception of this study.

This investigation is an attempt to substantiate the relationship between one's somatotype and the ability to develop anaerobic capacity through participation in varsity athletics. Sheldon did extensive research relating morphology and physiology (13). He concluded that certain body types re-occur among participants of given athletic activities.

Tanner corroborated the earlier findings of Sheldon (14). Through analysis of anthropometric measurements, photographs, and radiographs of 237 participants in the British Empire Commonwealth Games, he made the observation that each athletic speciality possesses a well defined average somatotype. As a result of these findings he asserted that physical differences alone are the cause of success or lack of it, and not training.

One might hypothesize from the above studies that physique and the ability to develop anaerobic fitness are linked by a common denominator, possibly genetic structure. No study to date has attempted to relate these two variables. One might conjecture, for example, that gymnasts, sprinters, and football players have high anaerobic reserves because of the combined influences of physique and conditioning. Participants in each of these sports are typically strong and robust individuals whose bodies are highly mesomorphic and 
well designed for power. Likewise, the intrinsic nature of gymnastics, football, and sprinting puts repeated demands on anaerobic reserves as a result of the high intensity and short duration of the work periods.

\section{Physical Activity and Anaerobic Capacity}

Physical activity is made possible through the oxidation of foodstuffs. Energy not directly supplied through oxidative processes must be obtained from anaerobic sources. Such is summarized by Margaria et al. as follows:

In supramaximal exexcise the extra energy which is not met by oxidation is drawn from splitting highenergy phosphate, and only when this source is exhausted is energy drawn from the other anaerobic source, the splitting of glycogen into lactic acid. (10)

Several investigators have recently explored the relationship between physical activity and anaerobic capacity. Hermansen noted that studies with animals demonstrate the fact that ATP and phosphocreatin are increased during training (5). Doe found a seven-week aerobic interval training program had little or no effect on total body lactate but contributed significantly to improvement of variables associated with aerobic capacity, i.e., maximum oxygen consumption, pulmonary ventilation, and capacity for work output (2).

It is well substantiated that the relative importance of the two energy systems (anaerobic and aerobic) are contin- 
gent upon the duration and intensity of work. Margaria et al. found that pyruvic acid in the blood increases exponentially with the intensity of work (9). Lactic acid also increases as a linear function of the intensity of work and reaches a plateau toward the end of exercise when maximal values are reached. Williams et al. examined the concentrations of lactate and pyruvate in the blood of thirteen subjects at three aerobic and four anaerobic levels of work before and following a period of training on a bicycle ergometer (16). Results showed that maximum $\dot{v o}_{2}$, and the level at which excess lactate appeared in the blood, changed independently during training. Throughout the period of training the mean level of oxygen intake, expressed as a per cent of the maximum value, increased from $46 \%$ to $62 \%$. In untrained individuals the onset of anaerobic metabolism occurred at $40 \%-45 \%$ of the maximum oxygen intake; in trained individuals, at 55\%-60\%; and in the well trained, at $70 \%$.

Costill conducted examinations on distance runners to determine the change in blood lactate during prolonged, exhaustive running at varied intensities and duration (I). He found an inverse curvilinear relationship between length of the competitive race and blood lactate concentration. The highly trained distance runners were found capable of utilizing more than $90 \%$ of their maximum $\dot{v}_{2}(X=70 \mathrm{ml} / \mathrm{kg}-\mathrm{min}$.$) for$ 25-30 minutes with only minimal accumulation of blood lactate. 
Karlsson and Saltin investigated the dynamics of lactate accumulation in working muscles, coupled with the breakdown of phosphogens for given intervals during the performance of a maximal bicycle exercise (7). Results demonstrated that the breakdown of ATP and phosphocreatin (PC) was maximal after two minutes of work. The accumulation of lactate in the muscle and in the blood, however, increased continuously until exhaustion. The results of this study concur with the earlier findings of Margaria.

Results are lacking concerning the relationship between physique and anaerobic capacity, as well as in the development of anaerobic capacity as a function of participation in selected physical activities. One might speculate that those activities characterized by power events should make the greatest contribution to the development of anaerobic capacity. One might further speculate that an individual with a powerful, mesomorphic physique with relatively short limbs is structurally better adapted for strength than for endurance. This physique would further possess a greater anaerobic capacity than its long-limbed, ectomorphic counterpart, such as the body Tanner identifies with long-distance runners (14).

\section{Statement of the Problem}

It is the purpose of this study to investigate the relationship between one's somatotype and the ability to 
develop anaerobic capacity through participation in varsity athletics.

\section{$\underline{\text { Sub-problems }}$}

1. To compare anaerobic capacity among somatotypes: endomorphs, mesomorphs, and ectomorphs.

2. To compare anaerobic capacity among participants in selected varsity sports.

3. To investigate the relationship between body type and participation in selected varsity sports.

4. To determine if anaerobic capacity improves differentially as a function of the following:

(1) somatotype; and (2) participation in selected varsity sports. 
CHAPTER II

\section{METHODS AND PROCEDURES}

As the purpose of this study was to quantitate (1) the effects of participation in varsity athletics on anaerobic fitness, and (2) the relationship of somatotype to the development of anaerobic fitness, the following variables were measured: somatotype, anaerobic power, and lactic acid production, following a short exhaustive run on a motordriven treadmill.

\section{Somatotype}

Morphological conformations were determined by utilizing the Heath-Carter Anthropometric Somatotype Rating Method (Appendix D). Necessary anthropometric measurements were taken with the following instruments: a pair of Lange skinfold calipers, a Gulick tape, a sliding wood caliper, a platform scale, and a Broca Plane. Physique was described in terms of a three-numeral rating, each numeral representing one of the three primary components of physique: (1) endomorphy; (2) mesomorphy; and (3) ectomorphy.

Endomorphy--The relative fatness of an individual's physique. Mesomorphy--The relative musculo-skeletal component of one's physique. 
Ectomorphy--The relative linearity of one's physique. (4)

\section{Anaerobic Power}

To indirectly measure anaerobic power, the MargariaKalamen Test of Anaerobic Power was employed. For such, the subjects took a six-meter running start towards a flight of stairs. They continued to run as rapidly as possible up the stairs, taking them three at a time, so that contact was made with stairs 3, 6, and 9. The time it took each subject to run between stair No. 3 and stair No. 9 was recorded with the aid of photoelectric cells and a Dekan timer sensitive to .01 of a second. The photoelectric cells were situated so that when contact with stair No. 3 was made, a light beam was broken and the timer was started. Contact with stair No. 9 activated a second photoelectric cell which in turn stopped the timer. Power was computed by multiplying the subject's weight by the verticle height between the first and last test stairs and dividing by the recorded time. Each subject was given ten trials, the best five of which were averaged to determine the subject's score.

\section{Lactic Acid}

To reflect the effect of training on the subject's anaerobic capacity, subjects were given short, exhaustive runs on the treadmill on a pre- and post-training basis. Prior to the first short, exhaustive run, practice trials 
were conducted to acquaint subjects with the treadmill and to determine individually the speed that would exhaust the subject in approximately 1 minute and 30 seconds. Lactic acid levels were determined at rest and five minutes following termination of the treadmill run. Approximately $10 \mathrm{cc}$ of blood were drawn from the medial cubital vein. Blood was immediately oxilated and determinations were made using the enzymatic method (11).

\section{Workouts}

Subjects were members of one of the six varsity teams investigated: football, soccer, basketball, wrestling, gymnastics, and cross country. These teams were part of the program offered by the Department of Physical Education and Athletics at California State College at Los Angeles. As such, they were given academic credit and met on a regularly scheduled basis. The conditioning program included those activities indigenous to each of the given sports (Appendix C). No specialized training program was imposed on any of the teams represented. All subjects were tested before and after eight weeks of practice and participation in their selected sports.

\section{Procedures}

Fifty-two healthy, varsity, male athletes from California State College at Los Angeles were subjects for this study. They represented members of the six sports under 
investigation. The number of participants from each of the sports is contained in Table 1 .

TABLE 1

VITAL DATA OF SUBJECTS PER SPORT

IN MEAN VALUES

\begin{tabular}{lrlll}
\hline \multicolumn{1}{c}{ Sport } & $\mathrm{N}$ & $\begin{array}{c}\text { Age } \\
\text { yrs. }\end{array}$ & $\begin{array}{c}\text { Height } \\
\text { cm. }\end{array}$ & $\begin{array}{c}\text { Weight } \\
\text { kg. }\end{array}$ \\
\hline Football & 17 & 20.8 & 171.9 & 86.2 \\
Soccer & 3 & 20.0 & 180.8 & 78.9 \\
Basketball & 9 & 22.0 & 185.3 & 81.8 \\
Wrestling & 8 & 20.4 & 176.1 & 79.7 \\
Gymnastics & 9 & 19.5 & 171.7 & 63.7 \\
Cross Country & 5 & 20.0 & 174.0 & 61.3 \\
\hline
\end{tabular}

Testing was conducted in the Human Performance

Laboratory at California State College at Los Angeles. Prior to testing, the subjects were oriented to the equipment and procedures.

Following orientation, the subjects reported to the laboratory in tennis shoes and gym shorts. Vital data were gathered as follows: name, height, weight, age, and athletic speciality. Arithmetic means for these data are contained in Tables 1 and 2 .

Each subject was then somatotyped by the Heath-Carter Anthropometric Technique. Following completion of these items the Margaria-Kalamen Test of Anaerobic Power was administered to each of the subjects. 
TABLE 2

VITAL DATA OF SUBJECTS PER SOMATOTYPE

IN MEAN VALUES

\begin{tabular}{lrlcr}
\hline Somatotype & $\mathrm{N}$ & $\begin{array}{l}\text { Age } \\
\text { yrs. }\end{array}$ & $\begin{array}{c}\text { Height } \\
\text { cm. }\end{array}$ & $\begin{array}{c}\text { Weight } \\
\text { kg. }\end{array}$ \\
\hline Endomorphs & 5 & 20.8 & 182.4 & 103.4 \\
Mesomorphs & 37 & 20.6 & 179.2 & 78.4 \\
Ectomorphs & 9 & 19.4 & 175.7 & 62.2 \\
\hline
\end{tabular}

Two subjects from each of the sports were randomly selected to be included in the blood lactate analysis. Following a training and orientation session on the treadmill, the twelve men selected for the lactate analysis were exercised on the treadmill at a $15.3 \%$ grade and at a speed individually determined to exhaust them at approximately 1 minute and 30 seconds.

At the end of an eight-week period of conditioning and competition in their selected sport, all subjects were retested on the Margaria-Kalamen Test of Anaerobic Power. Eleven of the original twelve men (one subject was lost due to injury) were retested on the short, exhausting treadmill run. Again, both resting and post-exercise lactate determinations were made on these subjects. 


\section{CHAPTER III}

\section{ANALYSIS OF DATA}

Data were analyzed to determine the effect of participation in varsity athletics upon anaerobic capacity, and to further illucidate the relationship of somatotype to the development of anaerobic fitness. Intra-sport improvement was analyzed by t-tests for matched samples. Improvement between pre- and post-training testing among the six varsity sports investigated was analyzed by means of covariance. The findings of this investigation were submitted to a directional hypothesis and interpreted in accordance with accepted statistical criteria.

\section{Anaerobic Capacity}

Anaerobic capacity was evaluated before and following eight weeks of participation in the following selected varsity sports: football, soccer, basketball, wrestling, gymnastics, and cross country. All subjects took the Margaria-Kalamen Test of Anaerobic Power. Resting and post-exercise blood lactates were determined on eleven randomly selected subjects. 
Margaria-Kalamen Test

of Anaerobic Power

Tables 3 and 4 contain the results of a quantitative analysis of power reflected by the Margaria-Kalamen Test. Pre-test data revealed considerable variation in power among sports and somatotypes. Cross country runners ranked lowest with a meager average power output of $100.50 \mathrm{~kg} .-$ meters $/ \mathrm{sec}$. This was considerably inferior to the score obtained by the wrestling team, whose average on the Margaria-Kalamen Test was $174.00 \mathrm{~kg} \cdot-$ meters $/ \mathrm{sec}$.

TABLE 3

POWER IN KG.-METERS/SEC. PRIOR TO AND FOLLOWING PARTICIPATION IN VARSITY SPORTS

\begin{tabular}{lrrrrr}
\hline Sport & \multicolumn{4}{c}{ Means } & \\
\hline Football & $\mathrm{N}$ & Pre-Test & Post-Test & $\overline{\mathrm{x}}_{\mathrm{D}}$ & $t$ \\
Soccer & 17 & 164.2 & 176.9 & 12.7 & $2.23 *$ \\
Basketbal1 & 3 & 140.3 & 147.0 & 6.7 & 1.22 \\
Wrestling & 9 & 166.4 & 166.2 & -.2 & -.02 \\
Gymnastics & 8 & 174.0 & 179.8 & 5.8 & .78 \\
Cross Country & 9 & 125.8 & 139.0 & 13.2 & $3.04 *$ \\
& 5 & 100.5 & 116.5 & 16.0 & 2.31 \\
\hline
\end{tabular}

*Significance: $\mathrm{P} \leq .05$ 
TABLE 4

POWER IN KG.-METERS/SEC. OF VARIOUS SOMATOTYPES

PRIOR TO AND FOLLOWING PARTICIPATION

IN VARSITY SPORTS

\begin{tabular}{|c|c|c|c|c|c|}
\hline \multirow[b]{2}{*}{ Somatotype } & \multirow[b]{2}{*}{$\mathbf{N}$} & \multicolumn{2}{|c|}{ Means } & \multirow[b]{2}{*}{$\bar{x}_{D}$} & \multirow[b]{2}{*}{$t$} \\
\hline & & Pre-Test & Post-Test & & \\
\hline Endomorphs & 5 & 193.7 & 205.1 & 11.4 & 1.24 \\
\hline Mesomorphs & 37 & 150.3 & 161.2 & 10.9 & $3.42 *$ \\
\hline Ectomorphs & 9 & 134.1 & 136.1 & 2.0 & .30 \\
\hline
\end{tabular}

Similarly, pre-test data revealed substantial differences among somatotypes. Endomorphs led the other two somatotypes with an average score of $193.73 \mathrm{~kg} .-$ meters $/ \mathrm{sec}$. This was considerably higher than the average obtained by the mesomorphs $(150.33 \mathrm{~kg} .-$ meters $/ \mathrm{sec}$.$) . Such was excep-$ tionally superior to the score of the ectomorphs, who obtained a mean power output of $134.09 \mathrm{~kg} .-$ meters $/ \mathrm{sec}$.

Improvement was also analyzed in respect to (1) the selected sport, and (2) somatotype. Results indicate that anaerobic power attributed to the ATP-PC metabolic source was significantly improved through participation in the following varsity sports: football, gymnastics, and cross country running. Participants in soccer, basketball, and wrestling experienced no significant training effect on the metabolic system. 
In investigating anaerobic capacity as a function of somatotype, it was found that mesomorphs alone displayed significant improvement on the Margaria-Kalamen Test of Anaerobic Power following eight weeks of training.

Blood lactates

Blood lactate data at rest and following a short, exhaustive run are represented in respect to the selected sport, Table 5 , and by somatotype, Table 6 .

TABLE 5

BLOOD LACTATES IN Mg PER CENT OF ATHLETES PRIOR TO AND FOLLOWING PARTICIPATION IN VARSITY SPORTS

\begin{tabular}{|c|c|c|c|c|c|}
\hline Sport & $\mathbf{N}$ & Pre-Test & $\begin{array}{l}\text { Means } \\
\text { Post-Test }\end{array}$ & $\bar{x}_{D}$ & $t$ \\
\hline Football & 2 & 95.6 & 123.9 & 28.3 & 2.78 \\
\hline Basketball & 2 & 128.7 & 121.1 & -7.6 & -.53 \\
\hline Soccer & 1 & 102.0 & 108.7 & 6.7 & .00 \\
\hline Gymnastics & 2 & 114.7 & 127.4 & 12.7 & 1.08 \\
\hline Wrestling & 2 & 89.2 & 121.5 & 32.3 & .95 \\
\hline Cross Country & 2 & 93.1 & 130.3 & 37.2 & 5.37 \\
\hline
\end{tabular}


TABLE 6

BLOOD LACTATES IN Mg PER CENT OF VARIOUS SOMATOTYPES

PRIOR TO AND FOLLOWING PARTICIPATION

IN VARSITY SPORTS

\begin{tabular}{lcrrrr}
\hline & & \multicolumn{2}{c}{ Means } & \\
Somatotype & N & Pre-Test & Post-Test & \multicolumn{1}{c}{$\bar{X}_{\mathrm{D}}$} & $\mathrm{t}$ \\
\hline Endomorphs & 2 & 89.2 & 121.5 & 32.3 & .95 \\
Mesomorphs & 6 & 113.2 & 121.4 & 8.2 & 1.00 \\
Ectomorphs & 3 & 95.6 & 128.6 & 32.0 & $5.62 *$ \\
\hline
\end{tabular}

*Significance: $\quad \mathrm{p} \leq .05$

Resting levels were subtracted from post-exercise levels to yield net increases following an exhaustive treadmill run. Pre-training means showed considerable variation among somatotypes and among sports. Football and wrestling ranked lowest with $95.61 \mathrm{mg} . \%$ and $89.24 \mathrm{mg} . \%$ respectively. In contrast, the basketball and gymnastics teams started the season with relatively high lactate levels. The basketball team averaged $128.70 \mathrm{mg} . \%$ and the gymnastics team averaged $114.73 \mathrm{mg} . \%$.

Comparisons of somatotypes in pre-training lactate levels likewise revealed differential means. Mesomorphs displayed the highest level, averaging $113.32 \mathrm{mg} . \%$. Endomorphs and ectomorphs scored $89.24 \mathrm{mg} . \%$ and $95.65 \mathrm{mg} . \%$ respectively.

The t-tests for correlated samples detected no 
significant increases in lactate levels. All of the sports investigated, with the exception of basketball, demonstrated mean increases on post-season testing.

Likewise, all three somatotypes were found to have increased lactate levels following the eight-week period of conditioning. The ectomorphs only, exhibited an increase which was statistically significant.

\section{Difference in Improvement Among} Sports and Somatotypes

To determine if any difference existed in improvement among the sports' groups and somatotypes investigated, separate analyses of covariance were computed for each of the following problems:

1. To determine if any given sport was superior to ald others in increasing performance on the Margaria-Kalamen Test of Anaerobic Power;

2. To determine if performance on the MargariaKalamen Test of Anaerobic Power improved as a function of somatotype;

3. To determine if training in any given sport was superior to all others in its ability to increase blood lactate levels following a submaximal exhaustive run on the treadmill; and

4. To determine if blood lactate levels following a submaximal exhaustive run on the treadmill improved as a function of somatotype.

An analysis of covariance table for each of the above problems can be found in Appendix B. The results indicate that none of the F-ratios was significant. Thus, the null hypothesis was substantiated in all cases, indicating 
that no significant improvement occurred in either of the anaerobic systems as a result of somatotype or participation in a given varsity sport.

\section{Athletic Specialty and Somatotype}

Morphological conformations were determined for each subject by utilizing the Heath-Carter Anthropometric Somatotype Rating Method. Topological representations of these morphological conformations by sport are contained in Figures 1-6. It is readily apparent that participants in the selected sports were relatively homogenous in the somatotype particular to the sport. Cross country runners were predominantly ectomorphic, and heavyweight wrestlers were predominantly endomorphic; these represented the two most polarized groups. Participants of the remaining sports were in between with relatively high mesomorphic components.

\section{Discussion}

In examining the relationship of anaerobic capacity to participation in varsity athletics, several observations are of interest. Anaerobic capacity is equal to the sum of the capacities of the lactacid and alactacid components. These function independently. Several of the teams--football, gymnastics, and wrestling--scored high on one of the two anaerobic tests and relatively low on the second. Such findings apparently indicate the relative independence of these sources of energy. A man could thus have a well conditioned 


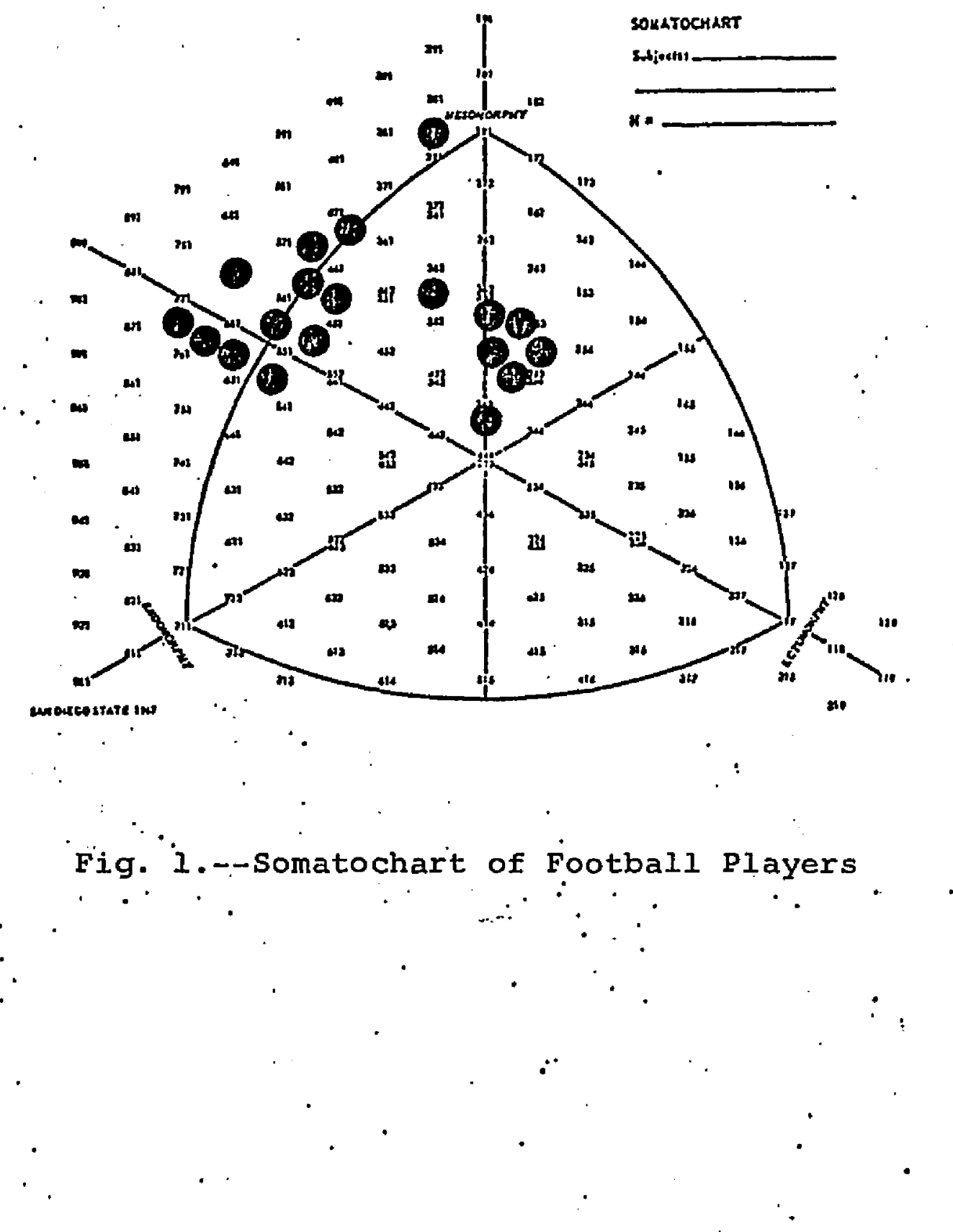




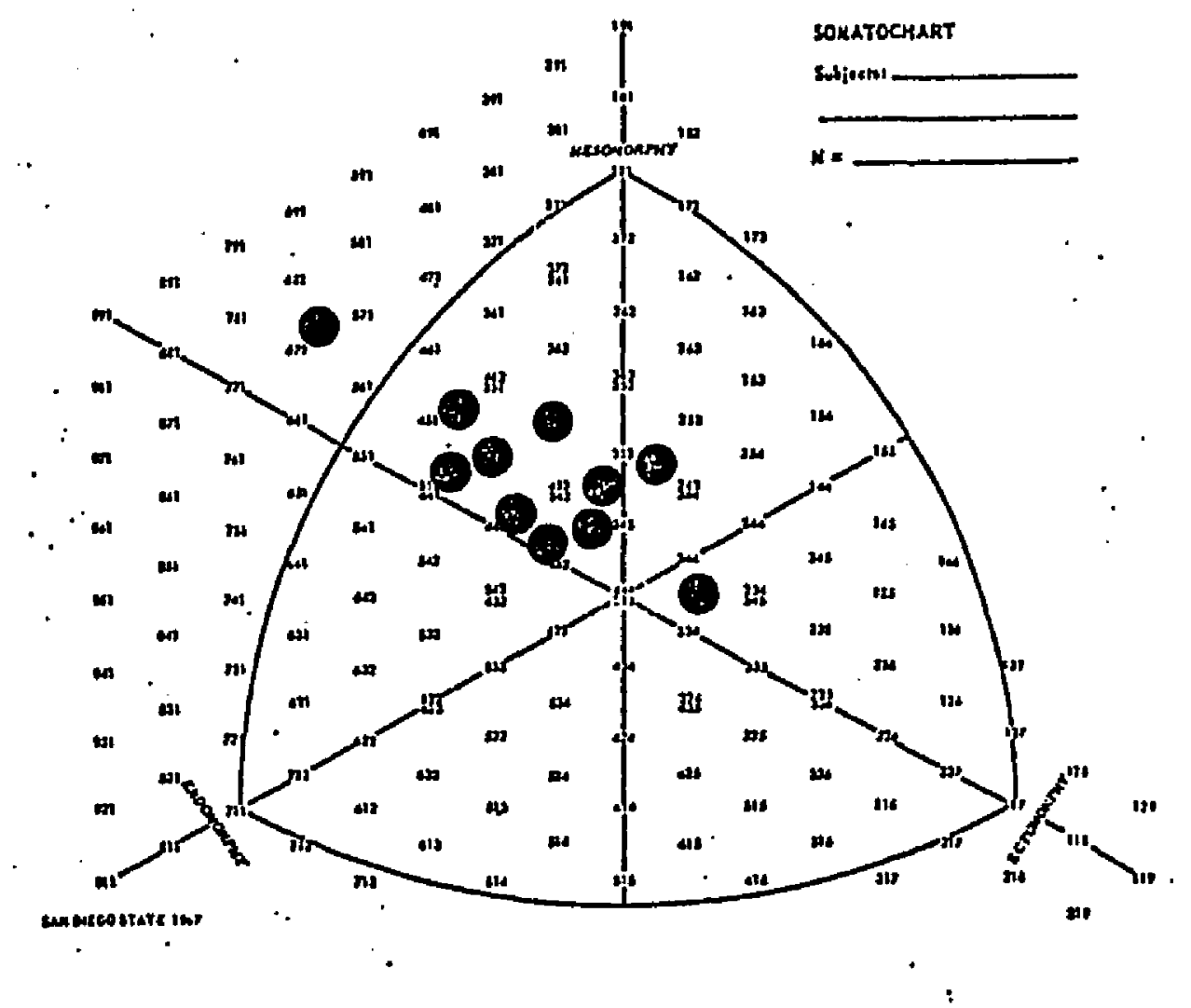

Fig:-2.--Somatochart of Soccer Players 


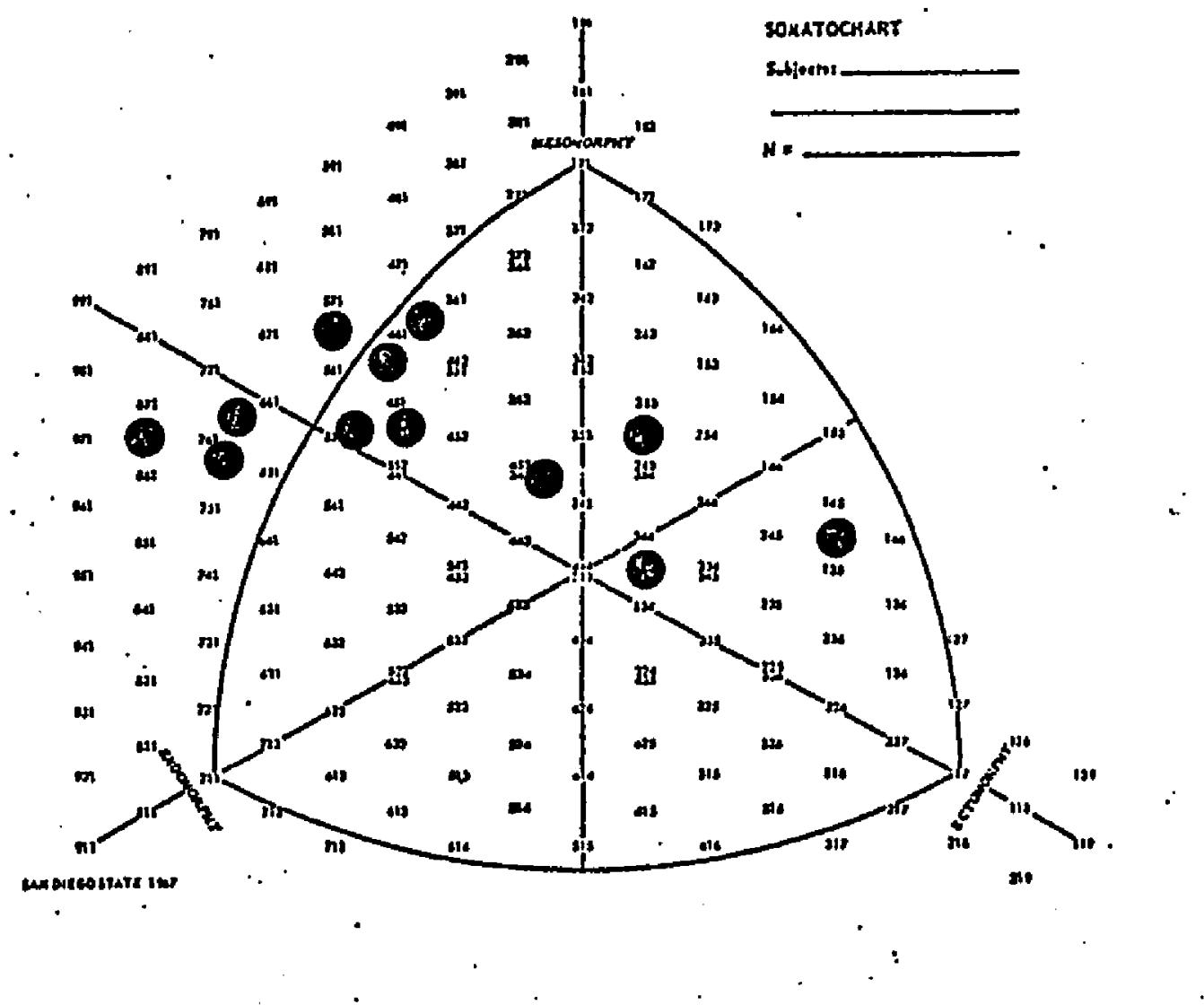

Fig. 3.--Somatochart of Wrestlers 




Fig. 4:--Somatochart of Basketball Players 


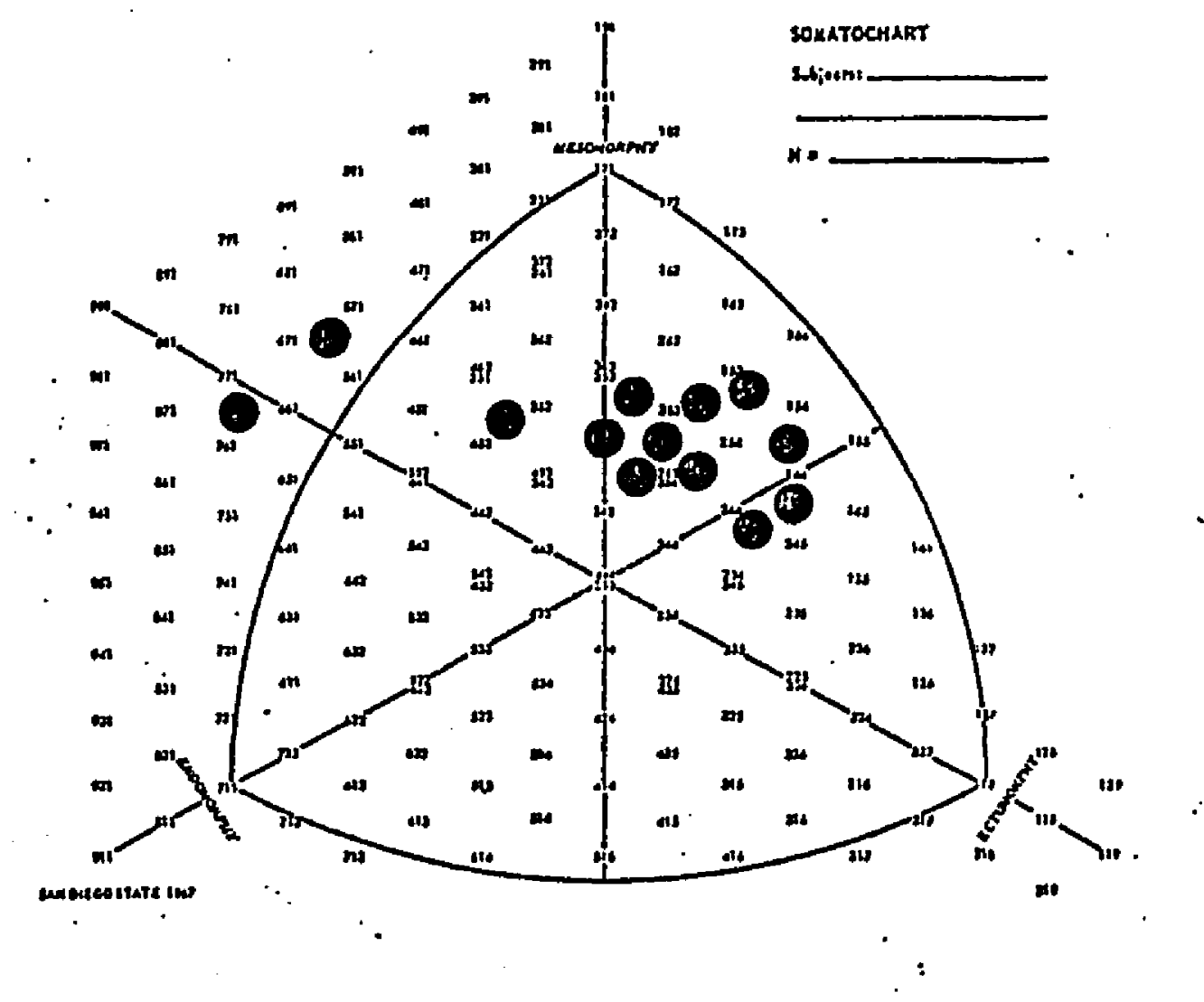

-Fig. 5.--somatochart of Gymnast 


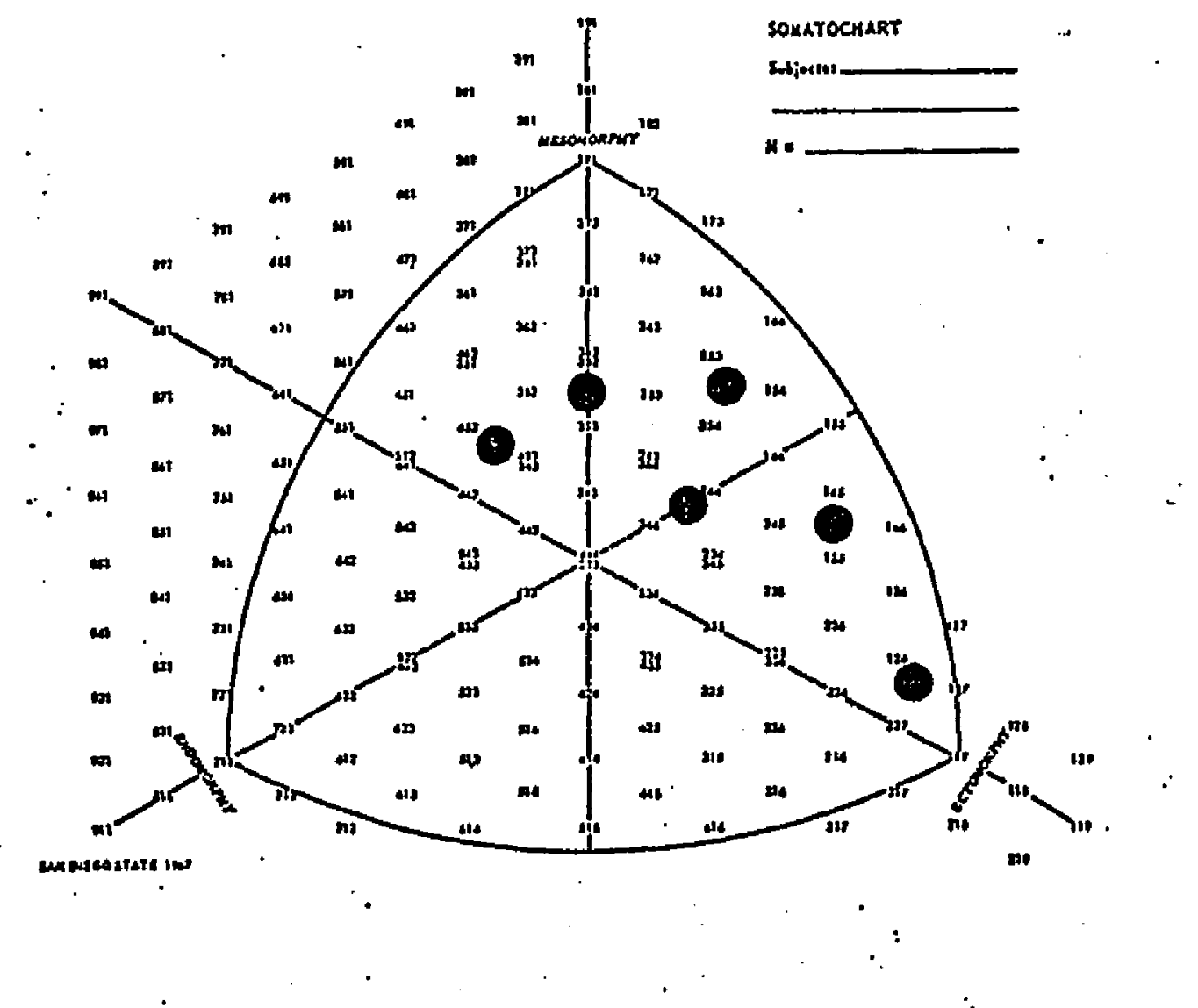

Fig. $6^{\circ}:-$-Somatochart of Cróss Country Runners 
alactacid system and a very limited capacity in terms of his glycolytic stores. This observation is supported by the association that exists between power demands that are indigenous to each of the selected sports and performance on the two criterion measures of anaerobic capacity chosen for this study. Football and wrestling, both activities characterized by high intensity and work periods of short duration, surpassed all other sports investigated in their contribution to the development of power as reflected by the MargariaKalamen Test. Cross country running, being a predominantly aerobic activity, scored lower than all other sports represented on this test.

The outcome of the evaluation of the total body lactates also provided insight. Except for basketball, all of the sports increased in post-exercise blood lactate levels following an exhaustive treadmill run as a result of the eight weeks of conditioning. Post-training variance among sports was considerably reduced over the pre-training data, indicating a more homogenous status with regard to the capacity of the lactic acid system as a consequence of training. Those sports with the lowest pre-training averages made the greatest gains over the eight-week conditioning period. One would expect the team with the poorest capacity to make the most substantial gain as a result of training, since the potential for improvement is obviousiy greater in the untrained than in the well conditioned athlete. The cross 
country runners experienced the greatest increment, with an average increase of $37.18 \mathrm{mg} . \%$ in total body lactate. closely following were the wrestling and football teams with increases of $32.22 \mathrm{mg} . \%$ and $28.26 \mathrm{mg} . \%$ of blood lactate respectively. Of particular interest was the finding that the gymnastics team surpassed both of these latter teams on post-training testing on this variable. One would expect this to occur, knowing that gymnastics' routines have a duration of one minute to one minute and a half. Thus, they put repeated stress on the lactic acid system. Post-season lactate levels for the cross country runners was a surprising development. However, an interview with the coach revealed that these men did some speed work and often trained on hilly terrain. A training regimen of this nature would stress anaerobic sources of energy, particularly glycolytic stores, and thus one would anticipate an increment in blood lactate levels following submaximal exhaustive exercise.

In relating anaerobic capacity to somatotype, it was demonstrated that increases in total body lactate levels were observed only among the ectomorphs. One might hypothesize that the lighter individual is more apt to participate in activities of low intensity but long duration than his heavier mesomorphic or endomorphic counterparts. Such was certainly exemplified in the cross country runners. These men represented the most ectomorphic team studied and also the team which made the most significant increases in blood 
lactate levels following a submaximal, exhaustive run on the treadmill. A second consideration is the unique training program given to the cross country team. This group trained on hilly terrain, and as previously discussed, such training would stress the lactic acid system and, therefore, one would expect a training effect to ensue.

In relating power and somatotype, it was demonstrated that the mesomorphs and endomorphs made substantial increases in anaerobic power as measured by the Margaria-Kalamen Test. Although these increments were equivalent in magnitude, because of variations in degrees of freedom, that obtained by the mesomorphs alone proved to be statistically significant. These findings confirm those of Tanner who found that activities characterized by power events favor participants with predominant musculo-skeletal development (15). Sprinters, gymnasts, and football players all have high mesomorphic components. Likewise, these activities constitute highintensity, short-duration activities. Consequently, one would expect mesomorphy or meso-endomorphy and power to be associated, although the nature of the alliance is unresolved. Do particular somatotypes gravitate towards those physical activities whose performance demands are complemented by the anatomical and physiological makeup of the individual? This seems feasible. Few heavy, fat men try out for cross country running; most applicants are tall, lean individuals. Likewise, few highly ectomorphic persons are apt to be found 
among the populace of shot-putters or discus throwers. Such observations, however, do not represent a cause and effect relationship. One could argue just as fervently that an individual is not a good long-distance runner because he is lean, but that he is lean because he is a long-distance runner. The observation in this study that cross country runners can make substantial increases in anaerobic capacity if trained anaerobically lends support to this premise. However, no conclusions can be arawn as a result of this investigation regarding the relationship between inherent physical aptitude and the effect of conditioning on athletic performance. The nature of this coalition remains unresolved in the perennial disquisition regarding nature and nurture. In summary, one might advise physical educators to take a good look at athletes in terms of structure as well as function in recruiting for competitive teams.

\section{Conclusions}

As a result of the data gathered in this study, several conclusions appear valid.

1. Participants in those varsity sports which are characterized by high-intensity, low-duration work periods made the greatest intra-group improvement in anaerobic capacity following participation in their selected sports.

2. Participants in varsity sports vary in anaerobic capacity. Wrestlers, football and basketball players were 
superior to participants in soccer, gymnastics, and cross country running in anzerobic reserves prior to conditioning.

3. When participants in the selected varsity sports were statistically equated, no athletic specialty proved superior in its ability to develop anaerobic capacity.

4. All somatotypes improved in anaerobic capacity as a result of training.

5. Endomorphs and Mesomorphs had the highest indigenous anaerobic capacity.

6. Mesomorphs exhibited significant intra-group improvement on the Margaria-Kalamen Test of Anaerobic Power following eight weeks of conditioning and training. Ectomorphs displayed statistically significant increases in total body lactate levels as a result of eight weeks of conditioning and training in their selected varsity sport. 
CHAPTER IV

\section{SUMMARY AND CONCLUSIONS}

As the purpose of this study was to quantitate (1) the effects of participation in varsity athletics on anaerobic fitness; and (2) the relationship of somatotype to the development of anaerobic fitness, the following variables were measured: somatotype, anaerobic power, and lactic acid production, following a short, exhaustive run on the treadmil1.

\section{Somatotype}

Morphological conformations were determined by utilizing the Heath-Carter Anthropometric Somatotype Rating Method. Physique was described in terms of a three-numeral rating. Each numeral represented one of the three primary components of physique: (1) endomorphy, (2) mesomorphy, and (3) ectomorphy.

\section{Anaerobic Power}

To indirectly measure anaerobic power, the MargariaKalamen Test of Anaerobic Power was employed. For such, the subjects took a six-meter running start towards a staircase, and continued to run as rapidly as possible up the stairs, 
taking them three at a time, so that contact was made with stairs 3,6 , and 9 .

A Dekan timer sensitive to .01 of a second was used to measure the net time between contact with steps 3 and 9 . Each subject was given ten trials, the best five of which were averaged to determine the subject's score.

\section{Lactic Acid}

To reflect the effect of training on anaerobic processes, subjects were given short, exhausting runs on the treadmill on a pre- and post-training basis. Prior to the first short, exhaustive run, practice trials were conducted to acquaint subjects with the treadmill and to determine individually the speed that would exhaust the subject in approximately 1 minute and 30 seconds. Lactic acid levels were determined at rest and five minutes following termination of the treadmill run. Approximately l0cc of blood were drawn from the medial cubital vein. Blood was immediately oxilated and determinations were made using the enzymatic method.

\section{Workouts}

Subjects were members of one of the six varsity teams investigated: football, soccer, basketball, wrestling, gymnastics, and cross country running. These teams were part of the program offered by the Department of Physical Education and Athletics at California State College at Los Angeles. As 
such, they were assigned academic credit and met on a regularly scheduled basis. The conditioning program included those activities indigenous to each of the given sports; no specialized training program was imposed on any of the teams represented. All subjects were tested before and after eight weeks of practice and participation in their selected sports.

\section{Summary and Conclusions}

The results of this study have demonstrated that anaerobic capacity is enhanced as a result of participation in varsity sports. The relative contribution of the given athletic specialty is associated with the indigenous nature of the sport. This study further demonstrated that somatotype and anaerobic capacity are also related, although the nature of the coalition remains unresolved in the perennial disquisition regarding nature and nurture.

As a result of the data gathered in this study, several conclusions appear valid.

1. Participants in those varsity sports which are characterized by high-intensity work periods of low duration made the greatest intra-group improvement in anaerobic capacity following participation in their selected sport.

2. Participants in varsity sports vary in anaerobic capacity. Wrestlers, football, and basketball players were superior to participants in soccer, gymnastics, and cross country running in anaerobic reserves prior to conditioning. 
3. When participants in the selected varsity sports were statistically equated, no athletic spëcialty proved superior to the others in its ability to develop anaerobic capacity.

4. All somatotypes improved in anaerobic capacity as a result of training.

5. Mesomorphs and Endomorphs had the highest indigenous anaerobic capacities.

6. Mesomorphs exhibited significant intra-group improvement on the Margaria-Kalamen Test of Anaerobic Power following eight weeks of conditioning and training. Ectomorphs displayed statistically significant increases in total body lactate levels as a result of eight weeks of conditioning and training in their selected varsity sports. 
APPENDIX A

VITAL DATA OF SUBJECTS 
VITAL DATA

\begin{tabular}{|c|c|c|c|c|c|c|c|c|c|c|c|c|}
\hline $\begin{array}{l}\text { Ini- } \\
\text { tial }\end{array}$ & $\begin{array}{l}\text { Age } \\
\text { yrs. }\end{array}$ & $\begin{array}{l}\text { Hgt. } \\
\text { in. }\end{array}$ & $\begin{array}{l}\text { Wgt. } \\
\text { lbs. }\end{array}$ & $\begin{array}{r}\text { Power } \\
\text { Pre-Train }\end{array}$ & $\begin{array}{l}\mathrm{kg} . \mathrm{m} / \mathrm{sec} .) \\
\text { Post-Train }\end{array}$ & Som & atot & ype & $\begin{array}{l}\text { Pre- } \\
\text { Rest }\end{array}$ & $\begin{array}{l}\text { Lacta } \\
\text { Prain } \\
\text { Po. } x\end{array}$ & $\begin{array}{r}\text { (mg\%) } \\
\text { Post } \\
\text { Rest }\end{array}$ & $\begin{array}{l}\text {-Train } \\
\text { Po. X }\end{array}$ \\
\hline & & & & & Footbal & & & & & & & \\
\hline $\begin{array}{l}\text { KG } \\
\text { OB } \\
\text { JV } \\
\text { BL } \\
\text { RS } \\
\text { DR } \\
\text { ML } \\
\text { GP } \\
\text { ET } \\
\text { NL } \\
\text { JM } \\
\text { DT } \\
\text { TY } \\
\text { BI } \\
\text { JL } \\
\text { AJ } \\
\text { TS }\end{array}$ & $\begin{array}{l}21 \\
21 \\
20 \\
20 \\
19 \\
19 \\
21 \\
20 \\
22 \\
21 \\
20 \\
21 \\
22 \\
21 \\
20 \\
22 \\
22\end{array}$ & $\begin{array}{l}71 \\
72 \\
71.5 \\
71 \\
72 \\
73.5 \\
71.5 \\
69 \\
73.5 \\
68.5 \\
70 \\
70 \\
68.5 \\
73 \\
71.5 \\
73 \\
72\end{array}$ & $\begin{array}{l}220 \\
164 \\
207 \\
165 \\
210 \\
212 \\
179 \\
156 \\
185 \\
170 \\
165 \\
174 \\
170 \\
174 \\
211 \\
249 \\
215\end{array}$ & $\begin{array}{l}21.3 .39 \\
154.83 \\
140.63 \\
145.40 \\
187.20 \\
165.12 \\
157.44 \\
136.18 \\
157.91 \\
181.64 \\
142.95 \\
118.21 \\
134.45 \\
185.91 \\
200.85 \\
196.58 \\
173.60\end{array}$ & $\begin{array}{l}281.96 \\
170.10 \\
175.72 \\
138.54 \\
208.04 \\
182.65 \\
186.10 \\
144.64 \\
145.06 \\
149.81 \\
155.79 \\
139.51 \\
136.31 \\
184.21 \\
189.91 \\
205.35 \\
213.46\end{array}$ & $\begin{array}{l}4 \frac{1}{2} \\
2 \frac{1}{2} \\
6 \\
2 \\
3 \frac{1}{2} \\
4 \frac{1}{2} \\
3 \\
2 \\
2 \\
4 \frac{1}{12} \\
2 \frac{1}{2} \\
5 \\
4 \frac{1}{2} \\
3 \\
6 \\
6 \frac{1}{2} \\
6 \frac{1}{2}\end{array}$ & $\begin{array}{l}6 \frac{1}{2} \\
4 \frac{1}{2} \\
7 \\
5 \frac{1}{2} \\
7 \frac{1}{2} \\
5 \frac{1}{12} \\
5 \frac{1}{2} \\
5 \\
4 \frac{1}{2} \\
4 \frac{1}{2} \\
5 \\
6 \\
5 \\
4 \\
5 \frac{1}{2} \\
6 \\
6\end{array}$ & $\begin{array}{l}3^{\frac{1}{2}} \\
1 \\
2 \frac{1}{2} \\
1 \\
1 \\
2 \\
2 \\
2 \\
1 \frac{1}{12} \\
2 \frac{1}{2} \\
1 \frac{1}{2} \\
1 \\
3 \\
1 \\
\frac{1}{12} \\
\frac{1}{2}\end{array}$ & $\begin{array}{r}2.80 \\
12.86\end{array}$ & $\begin{array}{l}102.10 \\
104.78\end{array}$ & $\begin{array}{l}27.80 \\
13.26\end{array}$ & $\begin{array}{l}145.20 \\
143.60\end{array}$ \\
\hline & & & & & Soccer & & & & & & & \\
\hline $\begin{array}{l}\text { GG } \\
\text { SM } \\
\text { BS }\end{array}$ & $\begin{array}{l}21 \\
18 \\
21\end{array}$ & $\begin{array}{l}72 \\
70 \\
71.5\end{array}$ & $\begin{array}{l}196 \\
170 \\
155\end{array}$ & $\begin{array}{l}163.09 \\
119.53 \\
138.18\end{array}$ & $\begin{array}{l}180.20 \\
118.10 \\
142.58\end{array}$ & $\begin{array}{l}4 \\
4 \frac{1}{2} \\
3 \frac{1}{2}\end{array}$ & $\begin{array}{l}4 \\
5 \\
4\end{array}$ & $\begin{array}{l}1 \frac{1}{2} \\
2 \\
3 \frac{1}{2}\end{array}$ & 13.53 & 115.50 & 3.90 & 112.60 \\
\hline
\end{tabular}


VITAL DATA--Continued

\begin{tabular}{|c|c|c|c|c|c|c|c|c|c|c|c|c|}
\hline \multirow[t]{2}{*}{$\begin{array}{l}\text { Ini- } \\
\text { tial }\end{array}$} & \multirow[t]{2}{*}{$\begin{array}{l}\text { Age } \\
\text { yrs. }\end{array}$} & \multirow[t]{2}{*}{$\begin{array}{l}\text { Hgt. } \\
\text { in. }\end{array}$} & \multirow[t]{2}{*}{$\begin{array}{l}\text { Wgt. } \\
\text { lbs. }\end{array}$} & \multicolumn{2}{|c|}{$\begin{array}{c}\text { Power (kg.-m/sec.) } \\
\text { Pre-Train Post-Train }\end{array}$} & \multicolumn{3}{|c|}{ Somatotype } & \multicolumn{4}{|c|}{$\begin{array}{ll}\quad \text { Lactates } & (\mathrm{mg} \%) \\
\text { Pre-Train } & \text { Post-Train } \\
\text { Rest Po. X } & \text { Rest Po. X }\end{array}$} \\
\hline & & & & \multicolumn{5}{|c|}{ Basketball } & & & & \\
\hline $\begin{array}{l}\text { JA } \\
\text { CV } \\
\text { TS } \\
\text { MS } \\
\text { MA } \\
\text { JD } \\
\text { MS } \\
\text { FJ } \\
\text { LD }\end{array}$ & $\begin{array}{l}27 \\
22 \\
20 \\
29 \\
20 \\
20 \\
20 \\
20 \\
20\end{array}$ & $\begin{array}{l}78 \\
69 \\
71 \\
69 \cdot 5 \\
71 \cdot 5 \\
77 \\
72.5 \\
74 \\
74\end{array}$ & $\begin{array}{l}235 \\
154 \\
168 \\
166 \\
170 \\
225 \\
174 \\
161 \\
166\end{array}$ & $\begin{array}{l}174.25 \\
120.32 \\
143.93 \\
133.58 \\
185.50 \\
206.55 \\
190.78 \\
161.24 \\
181.15\end{array}$ & $\begin{array}{l}199.14 \\
132.64 \\
147.20 \\
157.78 \\
173.63 \\
201.74 \\
153.64 \\
164.80 \\
165.53\end{array}$ & $\begin{array}{l}4 \frac{1}{2} \\
4 \\
3 \\
3 \\
3 \frac{1}{2} \\
6 \\
2 \frac{1}{2} \\
2 \frac{1}{2} \\
3\end{array}$ & $\begin{array}{l}6 \\
4 \\
4 \frac{1}{2} \\
5 \frac{1}{2} \\
4 \frac{1}{2} \\
5 \frac{1}{2} \\
4 \\
3 \\
3\end{array}$ & $\begin{array}{l}2 \\
2 \frac{1}{2} \\
2 \frac{1}{2} \\
2 \\
2 \frac{1}{2} \\
2 \\
3 \\
4 \\
4\end{array}$ & $\begin{array}{r}5.49 \\
19.30\end{array}$ & $\begin{array}{l}136.90 \\
145.3\end{array}$ & $\begin{array}{r}5.76 \\
10.85\end{array}$ & $\begin{array}{l}144.00 \\
119.80\end{array}$ \\
\hline \multicolumn{13}{|c|}{ Wrestling } \\
\hline $\begin{array}{l}\text { DW } \\
\text { GM } \\
\text { KM } \\
\text { JT } \\
\text { JF } \\
\text { TW } \\
\text { HC } \\
\mathrm{EE}\end{array}$ & $\begin{array}{l}20 \\
20 \\
21 \\
21 \\
22 \\
19 \\
23 \\
18\end{array}$ & $\begin{array}{l}70 \\
72 \cdot 5 \\
61 \cdot 5 \\
74 \cdot 5 \\
72 \\
71 \cdot 5 \\
65 \\
68\end{array}$ & $\begin{array}{l}177 \\
285 \\
100 \\
207 \\
170 \\
154 \\
169 \\
141\end{array}$ & $\begin{array}{l}173.12 \\
224.49 \\
115.35 \\
231.88 \\
198.12 \\
131.45 \\
196.96 \\
120.63\end{array}$ & $\begin{array}{l}195.90 \\
220.90 \\
113.37 \\
205.51 \\
194.20 \\
135.70 \\
242.08 \\
131.00\end{array}$ & $\begin{array}{l}6 \\
8 \frac{1}{2} \\
1 \frac{1}{2} \\
4 \frac{1}{2} \\
3 \frac{1}{2} \\
2 \frac{1}{2} \\
4 \\
2\end{array}$ & $\begin{array}{l}6 \\
6 \frac{1}{2} \\
3 \frac{1}{2} \\
5 \\
4 \frac{1}{2} \\
4 \\
6 \\
3 \frac{1}{2}\end{array}$ & $\begin{array}{l}1 \frac{1}{2} \\
\frac{1}{2} \\
3 \frac{1}{2} \\
1 \frac{1}{2} \\
3 \\
3 \frac{1}{2} \\
3^{\frac{1}{2}}\end{array}$ & $\begin{array}{l}10.85 \\
16.21\end{array}$ & $\begin{array}{l}100.76 \\
104.79\end{array}$ & $\begin{array}{r}4.02 \\
10.85\end{array}$ & $\begin{array}{r}159.98 \\
97.80\end{array}$ \\
\hline
\end{tabular}


VITAL DATA--Continued

\begin{tabular}{|c|c|c|c|c|c|c|c|c|c|c|c|c|}
\hline \multirow[t]{2}{*}{$\begin{array}{l}\text { Ini- } \\
\text { tial }\end{array}$} & \multirow[t]{2}{*}{$\begin{array}{l}\text { Age } \\
\text { yrs. }\end{array}$} & \multirow[t]{2}{*}{$\begin{array}{l}\text { Hgt. } \\
\text { in. }\end{array}$} & \multirow[t]{2}{*}{$\begin{array}{l}\text { Wgt. } \\
\text { Ibs. }\end{array}$} & \multirow[t]{2}{*}{$\begin{array}{r}\text { Power } 1 \\
\text { Pre-Train }\end{array}$} & \multirow[t]{2}{*}{$\begin{array}{l}(\mathrm{kg} .-\mathrm{m} / \mathrm{sec} .) \\
\text { Post-Train }\end{array}$} & \multicolumn{3}{|c|}{ Somatotype } & \multicolumn{2}{|c|}{$\begin{array}{l}\quad \text { Lactates } \\
\text { Pre-Train } \\
\text { Rest Po. } \mathrm{x}\end{array}$} & \multicolumn{2}{|c|}{$\begin{array}{l}\text { s }(\mathrm{mg} \%) \\
\text { Post-Train } \\
\text { Rest Po. X }\end{array}$} \\
\hline & & & & & & & & & & & & \\
\hline $\begin{array}{l}\text { LM } \\
\text { JS } \\
\text { SK } \\
\text { DS } \\
\text { DG } \\
\text { RG } \\
\text { ST } \\
\text { KA } \\
\text { CK }\end{array}$ & $\begin{array}{l}20 \\
18 \\
20 \\
19 \\
17 \\
18 \\
18 \\
19 \\
19\end{array}$ & $\begin{array}{l}69 \\
66 \\
65 \\
71.5 \\
66 \\
67 \\
71 \\
66 \\
68\end{array}$ & $\begin{array}{l}147 \\
114.5 \\
119 \\
146 \\
192 \\
144 \\
156.5 \\
144 \\
142\end{array}$ & $\begin{array}{r}116.72 \\
98.50 \\
123.98 \\
136.18 \\
151.59 \\
118.79 \\
155.70 \\
115.65 \\
115.46\end{array}$ & $\begin{array}{l}119.09 \\
130.13 \\
144.49 \\
134.82 \\
171.82 \\
134.04 \\
146.86 \\
137.07 \\
132.19\end{array}$ & $\begin{array}{l}2 \\
1 \frac{1}{2} \\
1 \frac{1}{2} \\
1 \frac{1}{2} \\
6 \\
2 \frac{1}{2} \\
2 \frac{1}{2} \\
4 \frac{1}{2} \\
2\end{array}$ & $\begin{array}{l}4 \frac{3}{2} \\
3 \frac{1}{2} \\
5 \\
4 \\
7 \\
5 \\
4 \frac{1}{2} \\
5 \frac{1}{2} \\
4 \frac{1}{2}\end{array}$ & $\begin{array}{l}3 \\
4 \frac{1}{2} \\
3 \frac{1}{2} \\
4 \\
\frac{1}{1 / 2} \\
2 \frac{1}{2} \\
3 \frac{1}{2} \\
2 \\
3\end{array}$ & $\begin{array}{r}5.49 \\
17.50\end{array}$ & $\begin{array}{l}134.27 \\
118.18\end{array}$ & $\begin{array}{r}4.92 \\
11.79\end{array}$ & $\begin{array}{l}134.00 \\
136.80\end{array}$ \\
\hline \multicolumn{13}{|c|}{ Cross Country } \\
\hline $\begin{array}{l}\text { JD } \\
\text { JL } \\
\text { MS } \\
\text { IM } \\
\text { EA }\end{array}$ & $\begin{array}{l}19 \\
19 \\
19 \\
20 \\
19\end{array}$ & $\begin{array}{l}69 \\
72.5 \\
66 \\
67.5 \\
67.5\end{array}$ & $\begin{array}{l}121 \\
136 \\
144.5 \\
130.5 \\
142\end{array}$ & $\begin{array}{r}104.24 \\
110.96 \\
122.89 \\
68.22 \\
96.19\end{array}$ & $\begin{array}{r}106.02 \\
115.65 \\
136.99 \\
86.74 \\
137.16\end{array}$ & $\begin{array}{l}1 \\
1 \\
2 \\
1 \frac{1}{2} \\
4\end{array}$ & $\begin{array}{l}3 \frac{1}{1 / 2} \\
2 \\
5 \frac{1}{1 / 2} \\
5 \frac{1}{2} \\
5\end{array}$ & $\begin{array}{l}5 \\
5 \frac{1}{2} \\
2 \\
3 \frac{1}{2} \\
2 \frac{1}{2}\end{array}$ & $\begin{array}{l}11.66 \\
11.25\end{array}$ & $\begin{array}{r}91.38 \\
112.80\end{array}$ & $\begin{array}{l}10.18 \\
12.99\end{array}$ & $\begin{array}{l}134 \\
149.80\end{array}$ \\
\hline
\end{tabular}


APPENDIX B

ANALYSIS OF COVARIANCE 




COEAFIGTTET TREATMENT XBETWEENA




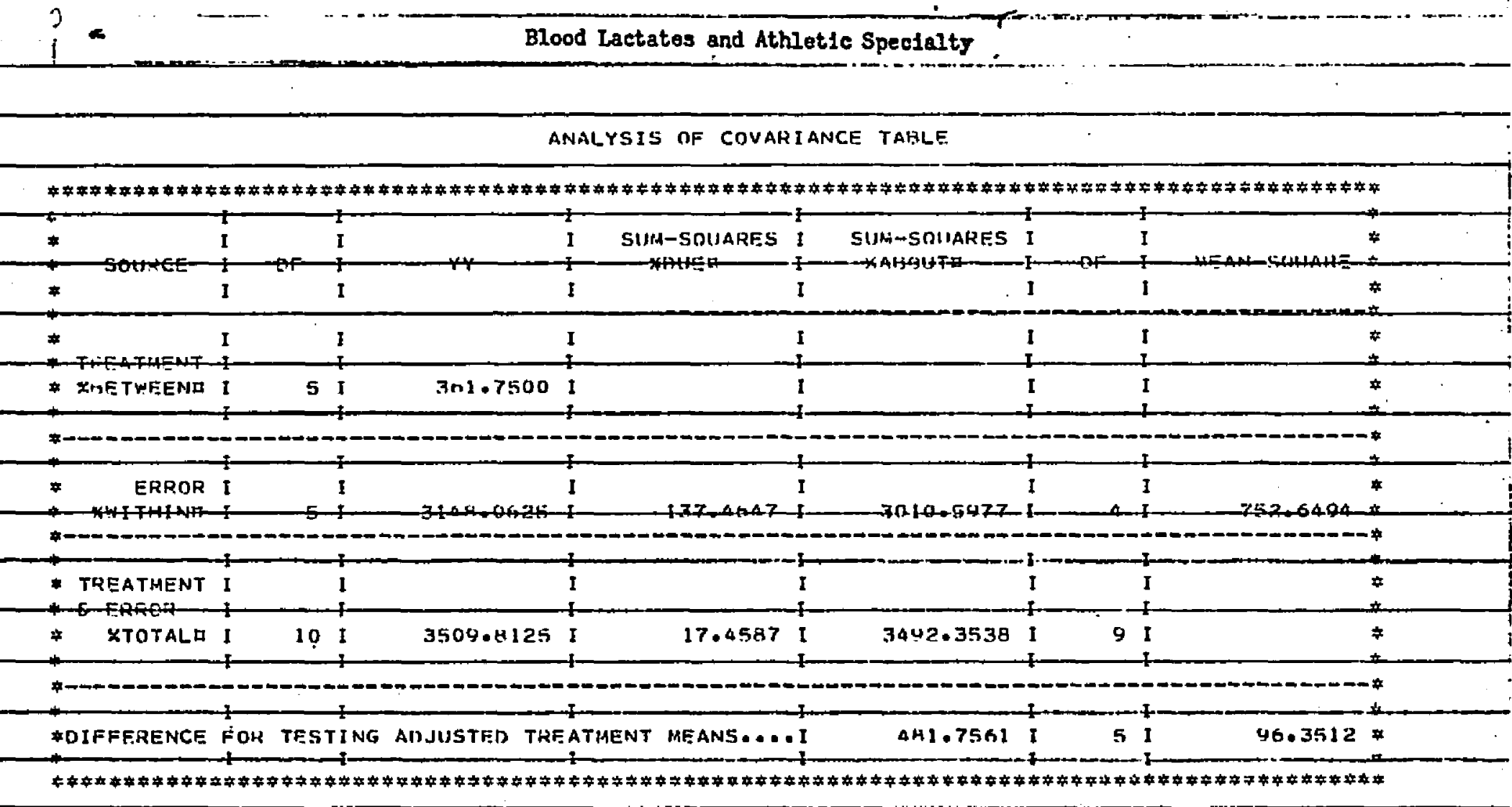

NULL HYPOTHESIS. NO DIFFERFNCE AMONG TRFATHENTS AFTER ADJHST THG WITH-GOVAHIATES.

F* 5. AaA $0.12 B$


ANALYSIS OF COVARIANCF TABLE

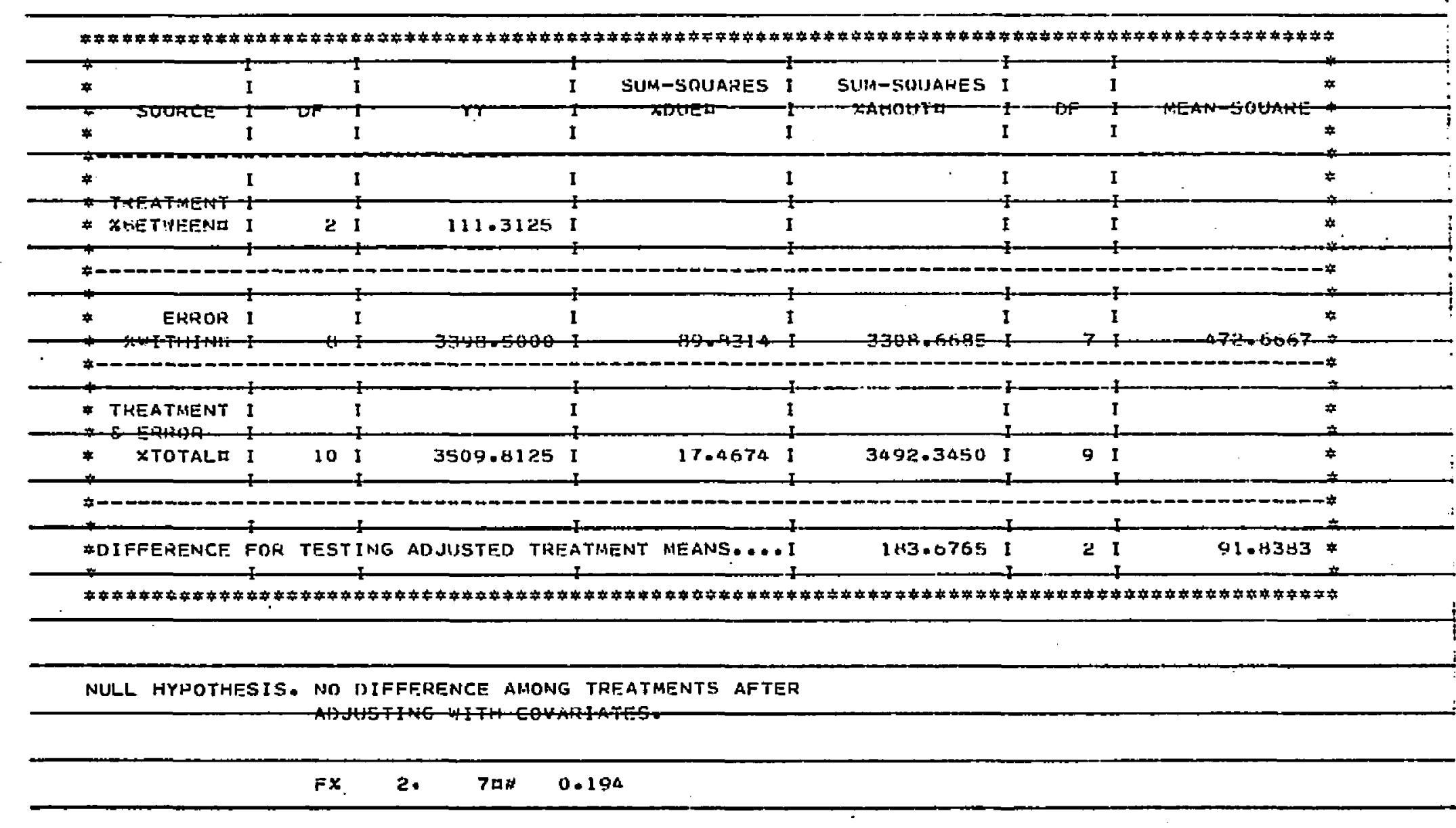

TAHE-OF COAEFICIFUTS

TREATMENT XEETWEEND 
APPENDIX C

DESCRIPTION OF WORKOUTS 
Sport: FOOTBALL

Coach: Robert Enger

Number of times pex week your team conditions or competes:

Five times--three condition, one compete, one think.

Nature of conditioning program:

Typical workout includes the following:

Work in small groups on individual skills--

10 minutes

Running--15-20 forty-yard sprints

Fundamentals--20 minutes

Practice scrimmage--40-60 minutes.

Relative amount of time spent to develop endurance as compared to strength or power:

Endurance--50\%

Power- $-50 \%$.

Duration of workout sessions:

At the beginning of the season there were two practices/day, two hours each; later in the season there was one practice/day, one and one-half hours in duration. 
Sport: SOCCER

Coach: Danny Bains

Number of times per week your team conditions or competes:

Two.

Nature of conditioning program:

Calisthenics, running, scrimmage.

Relative amount of time spent to develop endurance as compared to strength or power:

Endurance-- $90 \%$

Power--10\%.

Duration of workout sessions:

1.5 hours. 
Sport: BASKETBALL

Coach: Robert Miller

Number of times per week your team conditions or competes:

Six.

Nature of conditioning program:

Drills--emphasizing fundamentals and skills

Running--speed work, 15 minutes

Practice under game conditions.

Relative amount of time spent to develop endurance as compared to strength or power:

Integrated.

Duration of workout sessions:

Two hours and twenty minutes. 
Sport: WRESTLING

Coach: Reed Nilsen

Number of times per week your team conditions or competes:

Daily--usually two matches per week and three workouts.

Nature of conditioning program:

Our workouts consist of 10 or 15 minute warmups, which include lots of work on the neck and abdomen as well as concentration on upper body strength. We then go into a review of moves taught and use them as additional warmup drills to help develop conditioning. Next we introduce the move or moves we plan to work on for the day. Here are some examples: takedowns, breakdowns, escapes, reversals, rides, pins. These moves and many more not mentioned are worked on in sequence for a normal period of 30 to 40 minutes daily. Following such, we have a period of work on individual moves--about 20 minutes, then we have a period of 30 minutes of scrimmage, consisting of short 15 to 30 second scrimmages on certain selected phases of the moves mentioned above. The period ends with a good eight minutes of scrimmage to get acquainted with match time.

Relative amount of time spent to develop endurance as compared to strength or power:

This is hard to break down but I would guess that all total we attempt to spend about $60 \%$ of the time developing endurance, and $40 \%$ in the development of strength, power, and moves. This is hard to break down in wrestling because we use drills and moves that will encompass all--endurance, strength, power, and moves--at the same time.

Duration of workout sessions:

Two hours, followed by a two-mile run on their own. 
Sport: GYMNASTICS

Coach: Gordon Maddux

Number of times per week your team conditions or competes:

We work out at least five times a week pre-season and four times a week with one or two meets during the season.

Nature of conditioning program:

We spend the first four weeks working almost exclusively on new skills and new combinations of skills. This is followed by a transitional time, when the gymnast attempts to incorporate the old and the new into his competitive exercise. This second segment usually lasts from November 1 to about the Christmas break. From this time until the end of the season, the gymnast will first work two to four routines each time he practices the event, and then works on problem areas after routines are finished. This is the only form of endurance work we do. (However, the all-around man may do a total of 12 to 20 routines a day, and the specialist should shoot about 5 a day.) The first two months we work three events per day. Each day begins with about the same amount of time on strength work. After the second month we work six events a day.

Relative amount of time spent to develop endurance as compared to strength or power:

Very interrelated.

Duration of workout sessions:

Three hours for all-around and somewhat less for specialist. 
Sport: CROSS COUNTRY

Coach: Steve Haas

Number of tinnes per week your team conditions or competes: six to seven days per week.

Nature of conditioning program:

All running to build endurance, with a small amount of speed running.

Relative amount of time spent to develop endurance as compared to strength or power:

See above.

Duration of workout sessions:

Two sessions/day, about 5-7 miles each, taking about one hour. 
APPENDIX D

HEATH-CARTER ANTHROPOMETRIC SOMATOTYPE TECHNIQUE 
INSTRUCTIONS FOR CALCULATING THE HEATH-CARTER

ANTHROPOMETRIC SOMATOTYPE

\author{
J. E. Lindsay Carter \\ Department of Physical Education \\ San Diego state College \\ San Diego, California, U.S.A.
}

\begin{abstract}
Although the calculation of the Heath-Carter anthropometric somatotype is an objective procedure, the validity of the somatotype rating depends upon the reliabilities of the measurements used. The ten anthropometric measurements should be carefully taken according to the detailed instructions in the accompanying material "Anthropometric Measurement Techniques for Assessing Somatotype." Each investigator should demonstrate and report his reliability on the measurements. When comparing the distributions of two independent measures on the same subjects, the means should not differ significantly, and the Pearson product-moment $r$ should be above .90. Specifically, height and weight should have test-retest values of $r$.98; the girths and diameters $r$ 's between .92 and .98; and for the skinfolds, $r^{\prime} s$ between .90 and .96 are reasonable. Because skinfolds tend to be the least reliable measures and because the sum of three skinfolds is used for calculating endomorphy, the following procedures are recommended for use with all subjects.
\end{abstract}

a) Skinfolds, diameters, and girths are taken in this order.

b) The four skinfolds are repeated and recorded.

c) After the second series the following rules are applied.

i. If the second measure is not within $5 \%$

of the first measure, a third measure is

taken. For example: The recorder simply

says. "Repeat triceps and suprailiac,"

without informing the measurer of his

"scores."

ii. The two closest measures are averaged and entered on the rating form.

a) Either of the following procedures may be used to calculate reliability, depending on the investigator's purpose, but in both cases the $r$ for the sums of the skinfolds should be at least .95.

i. Sum three skinfolds (triceps, subscapular, suprailiac) for the first and second series and calculate the significance of the mean difference, and $r$. Same for calf. 
ii. Sum all four skinfolds and calculate the significance of $\bar{D}$, and $r$.

\section{Using the Heath-Carter Somatotype Rating Form}

The procedure for obtaining the somatotype rating from anthropometric data is described below.

1. Record pertinent identification data in the top section of the rating form. Give the name of the measurer. First Component (Endomorphy) rating (Steps 2-5) folds.

2. Record the measurements from each of the four skin-

3. Sum the triceps, subscapular, and suprailiac skinfolds and record in the box opposite TOTAL SKINFOLDS.

4. Circle the closest value in the TOTAL SKINFOLDS scale to the right. (Note: The scale reads vertically from low to high in columns, and horizontally left to right in rows. The rows, "lower limit" and "upper limit," are to provide exact boundaries for each column and these values should only be circled when the TOTAL SKINFOLDS are within a few milimeters of the limit. In most cases the value in the row "mid-point" is circled.)

5. Circle the value in the row FIRST COMPONENT which is directly under the column circled in number four above.

Second Component (Mesomorphy) rating (Steps 6-12)

6. Record the height (in.) and the humerus and femur diameters in the boxes. Before recording the biceps and calf girths in their respective boxes, the corrections for skinfolds must be made. To do this, subtract the triceps skinfold (convert to cm. first by dividing by 10) from the biceps girth, and subtract the calf skinfold (convert to $\mathrm{cm}$.) from the calf girth.

7. Mark the point of the subject's height on the height scale which is directly to the right. (Note: Regard the height row as a continuous scale.)

8. For each bone diameter and girth circle the figure in the proper row which is nearest the measurement. (Note: If the measurement falls exactly mid-way between two values, circle the lower value. Because the largest girths and diameters have been recorded the conservative procedure is used.) 
9. Now, deal only with columns, not numerical values. Find the column, or space between the columns, that is the average of the column deviations for the diameters and girths only (not height). To do this:

a) Consider as the zero column the left-most column containing a circled figure.

b) From this zero column, add the total number of columns you must travel horizontally to reach each of the other three circled numbers.

c) Divide this total by four.

d) Take the number obtained by this division and, starting at the zero column, count this number of columns to the right and place a mark (e.g. asterisk) at that point (whether the point be in the midale of a column or a fraction of the way between one column and the next).

10. Still considering columns only, count horizontally the number of columns you must travel from the asterisk to the marked height (or vice versa).

11. From the number 4 in the row marked SECOND COMPONENT move this number of columns to the right or left, depending upon the direction of the asterisk from the height marker. (If the asterisk is to the right of the height marker, move that number of columns to the right of number 4 , and if the asterisk is to the left, move left. Because the columns in this row are in half-unit increments, number of columns and half-unit increments (or decrements) are equivalent.)

12. Circle the closest SECOND COMPONENT value determined in 11 above. (If the point is exactly mid-way between two rating points, circle the value closest to the 4 on the scale. This regression toward the 4 is the conservative approach, and is less likely to produce spuriously extreme ratings.;

Third Component (Ectomorphy) rating (Steps 13-16)

13. Record the weight (1b.).

14. Refer to the nomograph to find the height-weight ratio (H.W.R., or height/ cube root of weight). Record the H.W.R. in the box.

15. Circle the closest value in the H.W.R. scale. (See Note in number 4 above.)

16. Locate the THIRD COMPONENT value below the column of the circled H.W.R. and circle it. 
The Heath-Carter Anthropometric Somatotype

17. Record the circled values obtained above in the appropriate columns in the row Anthropometric Somatotype.

18. The person calculating the rating should sign to the right.

J.E.L.C. October, 1969. 


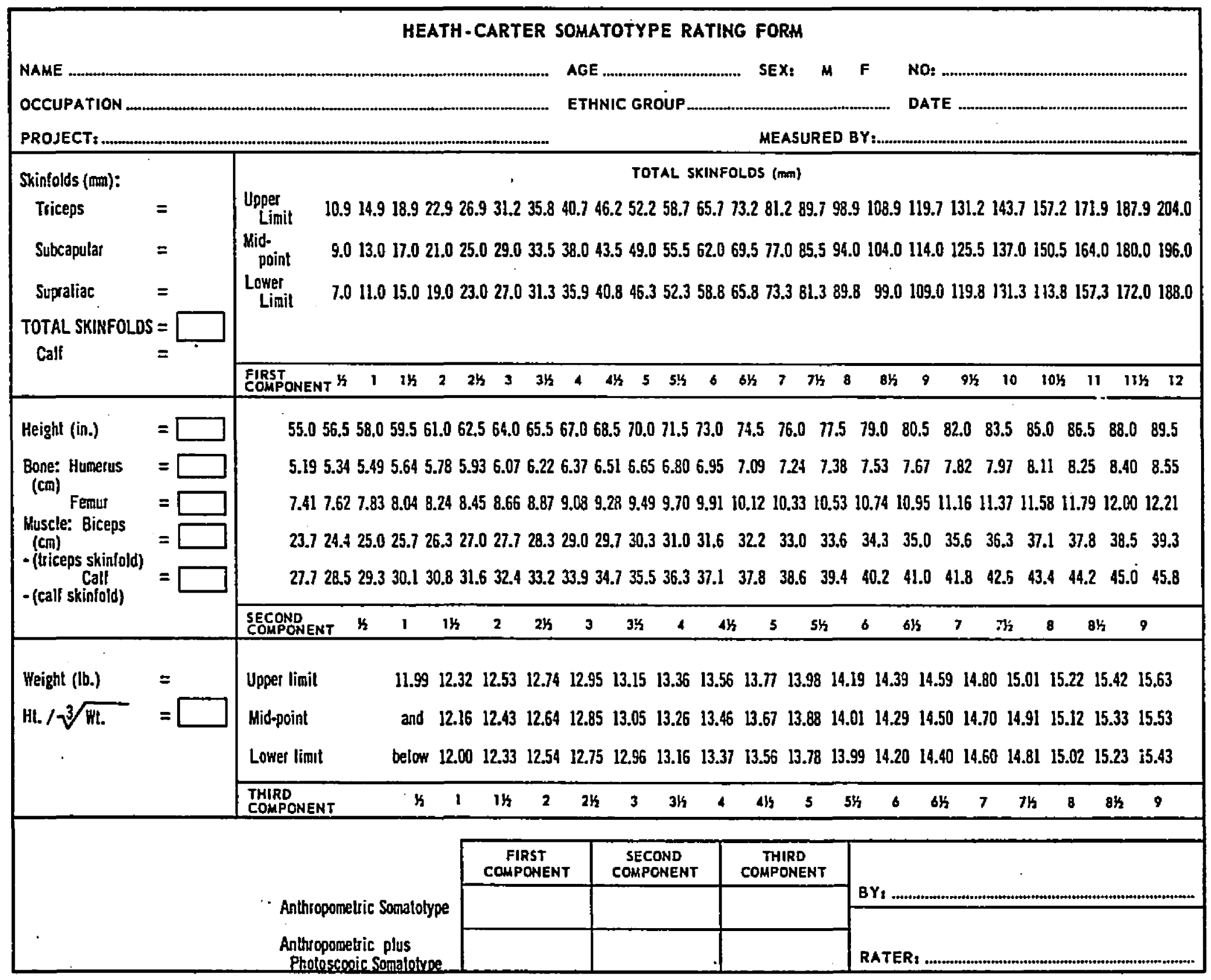


BIBLIOGRAPHY 


\section{BIBLIOGRAPHY}

1. Costill, D. "Metabolic Responses During Distance Running." Journal of Applied Physiology, 28:251255,1970 .

2. Doe, R. "The Metabolic Effects of a Seven-Week Aerobic Interval Training Program." Unpublished doctoral dissertation, The Ohio State University, Columbus, Ohio, 1970.

3. Hays, w. Statistics. New York: Holt, Rinehart, and Winston, 1963 .

4. Heath, B., and J. Carter. "A Modified Somatotype Method." American Journal of Physical Anthropology, $1: 57-74,1967$.

5. Hermansen, I. "Anaerobic Energy Release." Medicine and science in sport, 1:32-38, 1969.

6. Kalamen, J. "Measurement of Maximum Muscular Power in Mán." Unpublished doctoral dissertation, The Ohio State University, Columbus, Ohio, 1968.

7. Karlsson, J., and B. Saltin. "Lactate, ATP, and CP in Working Muscles during Exhaustive Exercise in Man." Journal of Applied Physiology, 29:598-602, 1970 .

8. Karpovich, P. Physiology of Muscular Activity. Philadelphia: W. $\bar{B}$. Saunders Company, 1965.

9. Margaria, R., et al. "Kinetics and Mechanism of Oxygen Debt Contraction in Man." Journal of Applied Physiology, $18: 371-377,1963$.

10. Margaria, R, et al. "Energy Utilization in Intermittent Exercise of Supramaximal Intensity." Journal of Applied Physiology, 26:752-756, 1969.

11. Pfleiderer, G., and K. Jose. "Eine Enzymatische Bestim-

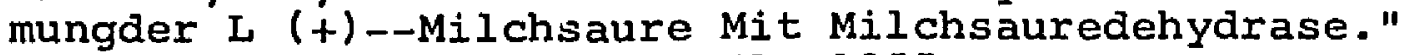
Biochemistry Z., 326:436-441, 1955 . 
12. Sheldon, w. Atlas of Men. New York: Harper \& Brothers, Publishers, 1954 .

13. Sheldon, $w$. The Varieties of Human Physique. New York: Hafner Publishing Company, 1963.

14. Tanner, J., et al. "Physique and Body Composition as Factors Affecting Success in Different Athletic Events." Medical Sport, 7:397-411, 1960 .

15. Tanner, J. The Physique of the Olympic Athlete. London: George Alien and Unwin Ltd, Ruskin House, 1964.

16. Williams, C., et al. "Effect of Training on Maximum Oxygen Uptake and on Anaerobic Metabolism in Man." Int. Z. Angew. Physiology, 241:18-23, 1967. 